\title{
Deterministic-statistical Model Coupling in a DSS for River-Basin Management
}

\author{
Jean-Luc de Kok • Martijn J. Booij
}

Received: 1 June 2007 / Accepted: 11 June 2008 /Published online: 26 July 2008

(C) The Author(s) 2008

\begin{abstract}
This paper presents a method for appropriate coupling of deterministic and statistical models. In the decision-support system for the Elbe river, a conceptual rainfall-runoff model is used to obtain the discharge statistics and corresponding average number of flood days, which is a key input variable for a rule-based model for floodplain vegetation. The required quality of the discharge time series cannot be determined by a sensitivity analysis because a deterministic model is linked to a statistical model. To solve the problem, artificial discharge time series are generated that mimic the hypothetical output of rainfallrunoff models of different accuracy. The results indicate that a feasible calibration of the rainfall-runoff model is sufficient to obtain consistency with the vegetation model in view of its sensitivity to changes in the number of flood days in the floodplains.
\end{abstract}

Keywords Decision-support system .

River-basin management - Appropriate modelling .

Model accuracy . Elbe $\cdot$ Floodplain vegetation model .

Rainfall-runoff model

\section{Introduction}

Given the growing complexity of river-basin management, there will be an increasing need for instruments that can

\section{J.-L. de Kok $\cdot$ M. J. Booij $(\square)$}

Department of Water Engineering and Management,

University of Twente,

P.O. Box 217, 7500 AE Enschede, The Netherlands

e-mail: m.j.booij@utwente.nl

J.-L. de Kok

e-mail: j.1.dekok@utwente.nl support the formulation of management strategies and facilitate discussions between scientists, decision makers, and stakeholders [1]. A decision support system (DSS) can facilitate river basin management by improving the level of understanding of the short- and long-term consequences of the interaction between the socio-economic, physical, and ecological processes and management measures. Essential conditions for successful application of a DSS include analysis of the problem from an integrated point of view, active involvement of end-users from the beginning of the design onwards, a clear statement of the purpose of the DSS, the presentation of results in a form tuned to the needs of the users, and a flexible design that can deal with changing demands [1]. The recently completed prototype DSS for the Elbe river basin [2-4] has been developed to support the task of analyzing, communicating, and implementing long-term river strategies involving flooding safety, floodplain vegetation, water quality, and inland navigation. To incorporate multiple river functions it is necessary to combine models and data pertaining to different processes and scientific disciplines. This raises the question to what extent models and data can be selected consistently in terms of the processes included, spatial and temporal resolution, and mathematical descriptions of the processes. Linking models and data, which differ considerably in one or more of these aspects, may result in a DSS that is not well-balanced and misleads its potential users due to a lack of transparency. Designing an internally consistent network of interacting models can be referred to as appropriate modelling. Others [5, 6] defined appropriateness on the basis of requirements on the model output accuracy. Both aspects, internal consistency and required output accuracy, have been combined in other appropriate modelling studies as well [7-11]. Concerning the aspect of internal consistency, problems may arise particularly when 
coupling models of different nature (e.g., qualitative vs. quantitative, deterministic vs. statistical, lumped vs. distributed, static vs. dynamic) within a DSS. For deterministicstatistical model coupling in a DSS, an important question is what the accuracy of the deterministic model should be, given the required input accuracy of the statistical model. Ideally, the model selection problem is solved prior to the calibration of the deterministic model in order to avoid unnecessary and time-consuming optimization and data collection, or choosing a model of an accuracy that exceeds the purpose of its application. The aim of this study is to provide a systematic and rapid approach for identifying which level of accuracy of a deterministic model is sufficient for coupling to a statistical model. Although the case example used concerns a deterministic rainfall-runoff model that is coupled to a statistical model for floodplain vegetation, the findings can be generalized to other types of models. The method comprises three steps to identify the appropriate level of accuracy of the deterministic model: generating artificial time series that represent the output of deterministic models of different accuracy, setting an accuracy standard for the input provided to the statistical model, and deriving a functional relationship between the output accuracy of the deterministic model and the required input accuracy of the statistical model. This relationship can then be used to translate the required input accuracy of the statistical model directly into an appropriate value for the accuracy of the output of the deterministic model.

The coupling of a rainfall-runoff model and a vegetation model in the prototype DSS [2] for several locations along the River Elbe serves as case example. The paper is organized as follows. Section 2 introduces the study area and provides an overview of the Elbe DSS. The model components that are relevant for the problem addressed in this paper are discussed in section 3. The method to estimate the appropriate level of accuracy of the rainfallrunoff model is elaborated in section 4 . The results of the application of this method and the effects of climate change on the vegetation patterns are described in section 5. The paper is concluded with a discussion section.

\section{The Elbe River Basin and Elbe DSS}

\subsection{Basin Characteristics}

The River Elbe is one of the largest rivers in Central Europe (Fig. 1). With the exception of the large cities of Dresden and Magdeburg, the river area is sparsely populated. The water quality in the river is affected by different diffusive sources of pollution, whereas industrial and urban centers form important point sources of pollution. In terms of shipping density, the river is second only after the River Rhine in Germany. Ongoing and planned engineering works aimed at improving the navigability of the river and reducing the risk of flooding include large-scale dike relocation, groyne restoration, and excavation of the river bed and floodplains. It is not obvious how the hydraulic and morphological consequences of these river engineering works will affect the vegetation conditions in the floodplains. In addition, uncertain demographic and climatic changes could influence the effectiveness of different combinations of measures.

Several sections of the river have been designated as protected nature reserves with vegetation types that form a habitat for rare fauna. The Middle Elbe region between the cities of Wittenberg and Aken is part of a UNESCO biosphere reserve [13].

\subsection{Structure of the Elbe DSS}

In order to support the preparation of long-term river strategies and improve the communication between scientists, stakeholders, and decision-makers, the German Federal Institute of Hydrology took the initiative to develop a prototype DSS for the German part of the River Elbe and its river basin [2-4]. The prototype tool was completed in 2005, and integrates models and data related to flood safety, inland navigation, vegetation ecology, and water quality. The formulation of appropriate long-term strategies for the Elbe river requires understanding of the interaction of measures with the socio-economic, ecological, and physical processes at different scale levels. To deal with the differences in spatial and temporal scales of the processes and the available models and data the DSS has been designed around four interacting modules (Fig. 2).

The catchment module describes the quality and quantity of runoff, as well as land use and the underlying hydrological characteristics. This module pertains to the scale of the German part of the river basin, and includes the conceptual rainfall-runoff model Hydrologiska Byråns Vattenbalansavdelning (HBV) or Hydrological Bureau Water Balance [14], which is used to model the river discharge for spatial rainfall patterns that reflect different climate conditions. The transport and degradation of substances due to diffuse and point sources of pollution in the main channel and connected tributaries are modeled in the river network module. A key function of these two modules is to generate discharge data used by the other two modules of the DSS, the channel module, and the river section module. These include several models with statistical input. The channel module describes the flood risk and shipping conditions along the main channel, as well as the vegetation types in the floodplains. The one-dimensional stationary flow hydraulic model HEC-6 [15] is used as 
Fig. 1 The Elbe river basin and the Middle Elbe biosphere reserve [12]

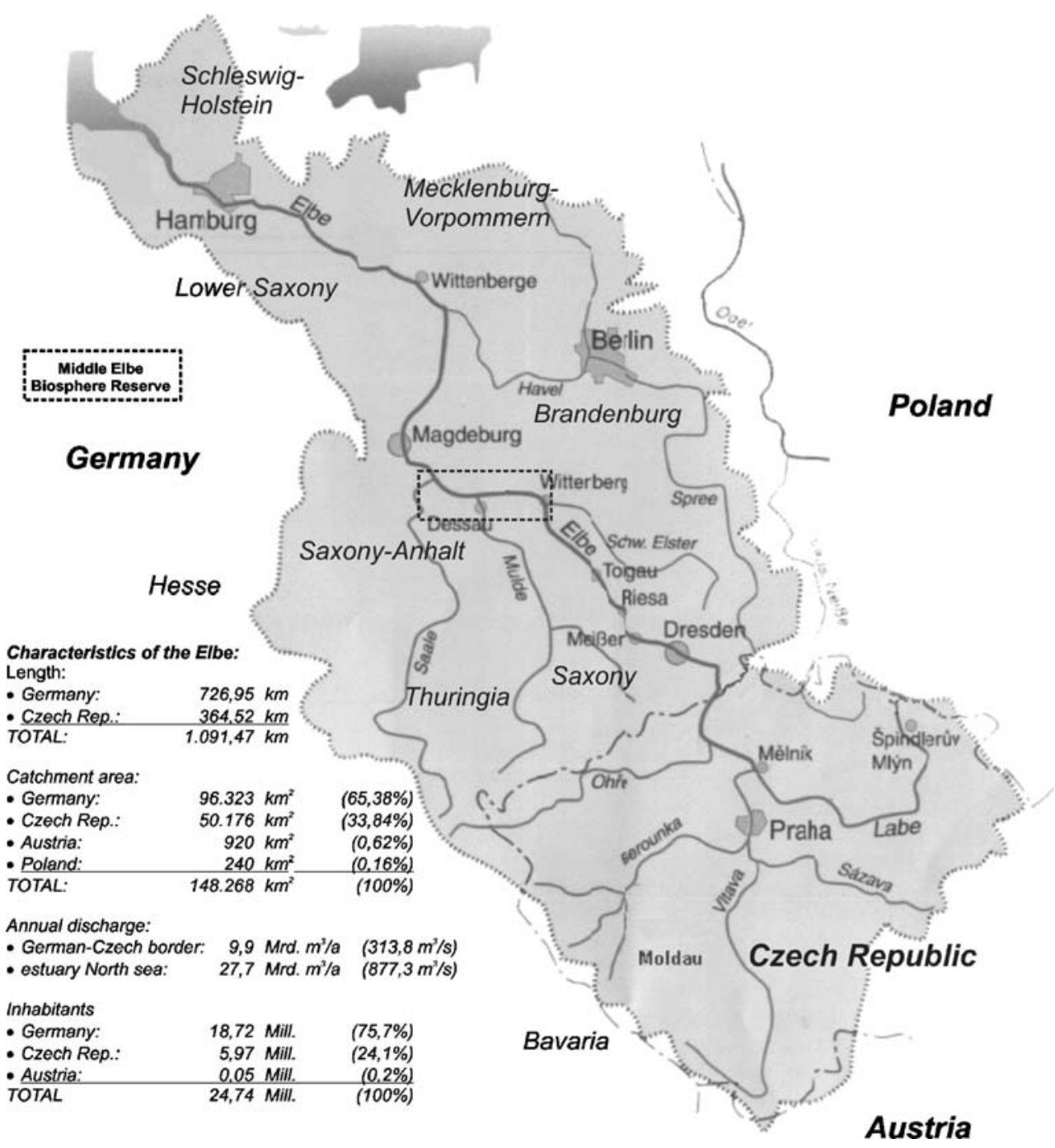

model core. The river section module presents the vegetation conditions and flood risk with more spatial detail for selected locations along the river. Throughout the project the system diagram (Fig. 2) was used to schematize the status of the design. This system diagram describes the relationships between the measures, scenarios, and management indicators for all the modules and served as a blueprint for the layout of the user interface. A more detailed description of the setup, data used, and application of the DSS is found in the online library description that comes with the DSS [2]. The focus in this study is on the coupling of a deterministic, rainfall-runoff model and a statistical, vegetation model. The vegetation model is the rule-based model MOVER2.2 [16], which simulates the response of the floodplain vegetation to changes in the hydraulic and hydrological conditions. A key input variable of MOVER2.2 is the average number of flood days in the floodplains, which is calculated from the local elevation, the water level, and the statistics for the average daily discharge. The rainfall-runoff model HBV [14] is used to simulate discharge time series at various locations along the main channel and tributaries of the German part of the river Elbe, from which the statistics for the average daily discharge are determined. Different climate scenarios can be chosen by the users to examine the potential effect of changes in the discharge statistics on the vegetation patterns.

\subsection{Data}

The available data for the Elbe river between the CzechGerman border (Elbe $\mathrm{km} \mathrm{0)}$ ) and the weir at Geesthacht (Elbe km 568) include river cross section profiles [15], a digital elevation model for the floodplains [17] that has been aggregated to a $100 \times 100 \mathrm{~m}$ raster grid in the DSS, the CORINE land use data [18], dike lines delineating the floodplains [19], and two maps to assign the distance to the main channel and the river kilometer chainage (counting downstream from the Czech-German border) to each cell in the floodplains. The river kilometer map is obtained by 

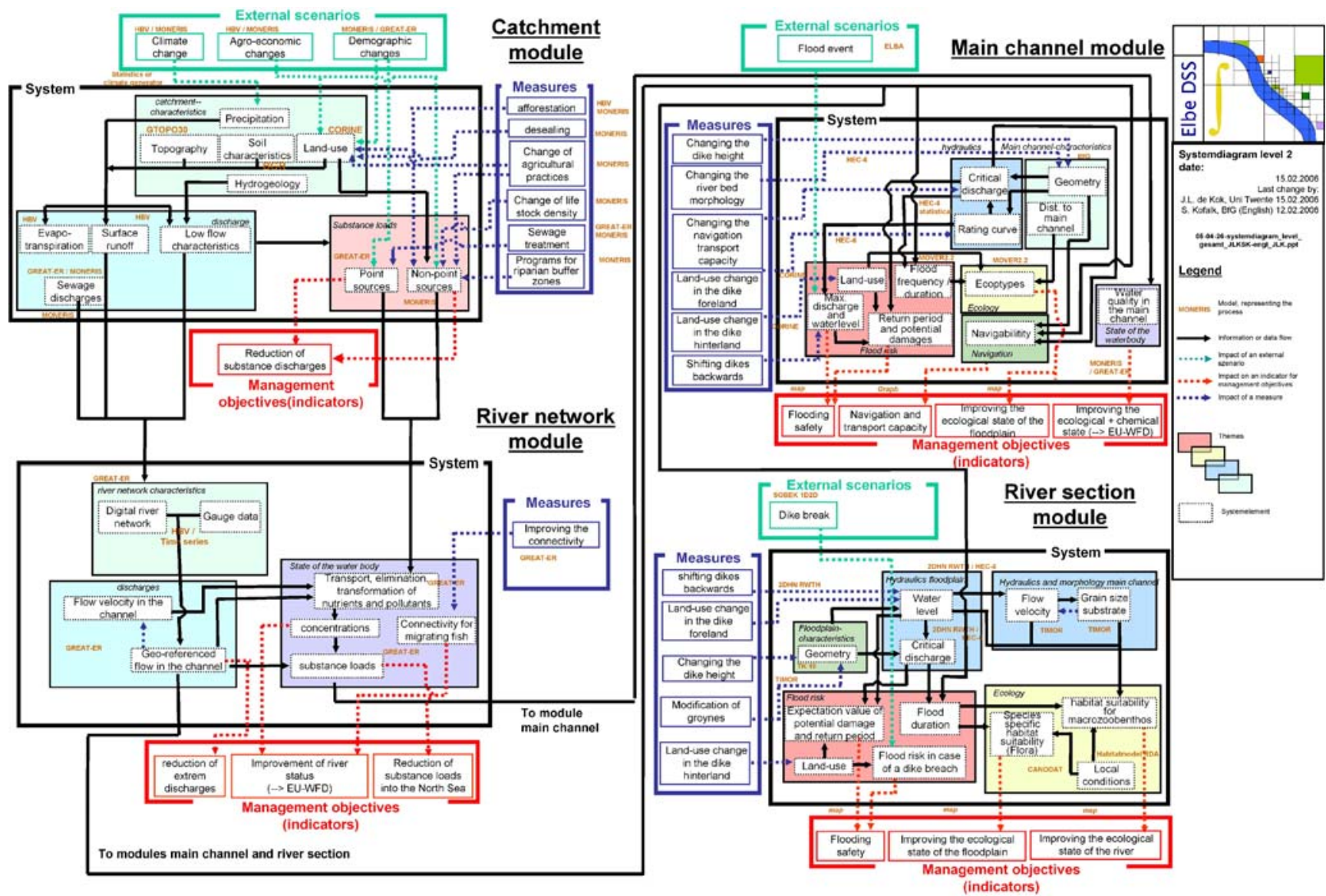

Fig. 2 Modular design structure of the Elbe DSS schematizing the dependencies between measures, scenarios, and indicators for the four DSS modules [2]

extrapolation of the cross profiles perpendicularly to the flow direction. Daily discharge, rainfall, and temperature data for the rainfall-runoff model HBV have been obtained from the German Hydrological Atlas [20]. These data are available for 84 temperature stations and 285 rainfall measuring stations for the time period 1951-2000. The monthly average potential evapotranspiration depends on the selected climate change scenario. For temperatures above $5^{\circ} \mathrm{C}$ the potential evapotranspiration was determined from the temperature and duration of sunshine by means of the Blaney-Criddle equation [21]. For temperatures below $5^{\circ} \mathrm{C}$, the evapotranspiration is determined from the temperature only by means of a modification of the equation of Ivanov [22]. The three climate scenarios that are available to the user of the DSS differ in terms of the rainfall trend and have been obtained with the regional climate model STAR of the Potsdam Institute for Climate Research [23, 24]; they consist of time series for rainfall (59 stations) and temperature (369 stations). The scenarios are based on a $1.4 \mathrm{~K}$ temperature trend for 2001-2055 and are taken from the coupled ocean-atmosphere model ECHAM4-OPYC3 [25], which forms the basis for the IPCC A1- $\mathrm{CO}_{2}$ emission scenario [26].

\section{The Models}

The chain of models, which are relevant for the topic of this paper consists of four different models that describe the effect of climate change on rainfall, the corresponding runoff, the water levels in the Elbe river, and finally the change of the dominant vegetation types in the floodplains.

\subsection{Deterministic Models}

\subsubsection{Climate Change}

The climate change scenarios consist of time series for the precipitation in milllimeter and the air temperature in degrees Celsius for each of the climate stations in the Elbe river basin, and have been determined with the STAR regional climate model $[23,24]$. The $\mathrm{A} 1-\mathrm{CO}_{2}$ emission scenario [26] is used, where a temperature trend of $1.4 \mathrm{~K}$ for the period 2001-2055 is assumed. A probability distribution with ten classes for the rainfall trend for 1951-2000 was obtained from 100 simulations with the STAR model [24], from which ten rainfall trend classes for the period 2001-2055 were obtained. The analysis was 
repeated for all measuring stations in the Elbe catchment. The most probable scenario is based on the assumption that the rainfall trend for the period 2001-2055 falls in the rainfall trend class corresponding to the trend observed for the period 1951-2000. In addition to the most probable rainfall scenario, the DSS user can choose a scenario without a rainfall trend and a scenario with a significant rainfall trend, which has been obtained by identifying the trend class with the largest rainfall trend. Furthermore, a reference scenario for the period 1979-1994 is included.

\subsubsection{Rainfall-runoff}

A distributed version of HBV [14] is incorporated in the Elbe DSS to describe the hydrological effects of the temperature and precipitation time series for the chosen climate change scenario. A wide range of HBV applications can be found in the literature from snowmeltdominated Scandinavian basins to tropical basins in Africa, Asia, and Latin America. Considerations in favor of HBV can be found in e.g. [27]. HBV describes the river basin hydrology conceptually, and simulates the river discharge as a function of precipitation, temperature, and evapotranspiration, corresponding to the selected climate scenario. The version of HBV in the Elbe DSS has been developed by Krysanova et al. [28] and comprises a snow module, a soil module, a runoff module, and a routing module. The river basin has been divided into 20 subbasins. This subdivision ensures that the discharge statistics needed for the hydraulic model (see section 3.1.3) are determined for a sufficient number of locations along the main channel. Each sub-basin has been calibrated with discharge data for the period 1980-1990 that were obtained from the hydrological atlas of the German Weather Service [20] and other sources [29, 30]. The calibration was aimed at optimization of the water balance expressed by the relative volume error RVE (\%) and the Nash-Sutcliffe coefficient NS [31]:

$$
\begin{gathered}
\mathrm{NS}=1 \frac{\sum_{t=1}^{T}\left[Q_{\mathrm{m}}(t)-Q_{\mathrm{o}}(t)\right]^{2}}{\sum_{t=1}^{T}\left[Q_{\mathrm{o}}(t)-\bar{Q}_{\mathrm{o}}\right]^{2}} \\
\mathrm{RVE}=100 \cdot \frac{\sum_{t=1}^{T}\left[Q_{\mathrm{m}}(t)-Q_{\mathrm{o}}(t)\right]}{\sum_{t=1}^{T} Q_{\mathrm{o}}(t)}
\end{gathered}
$$

where $t$ is the time step, $T$ is the total number of time steps, $Q$ is the discharge, and the subscripts o and $\mathrm{m}$ indicate the observed and modeled discharge values. Even for the perfect RVE value of zero, the distribution of the discharge during the year can be completely wrong. The NS coefficient has a range between $-\infty$ and 1 . An NS value of 1 reflects perfect agreement between the model and observations, whereas an NS value equal to zero indicates that the model and observations have the same variance. A negative $N S$ value occurs when the model produces meaningless results.

\subsubsection{Channel Hydraulics}

The one-dimensional hydraulic model HEC-6 [15] is used to determine stage-discharge relationships every $500 \mathrm{~m}$ along the Elbe river. HEC-6 numerically solves the energy equation with energy loss due to friction according to Manning's equation [32]. In the Elbe DSS the stagedischarge relationships are described with the power function

$h(x)=a(x) Q(x)^{b(x)}$,

where $x$ is the river location, $h$ is the water level in meter relative to the German standard level $\mathrm{NN}, Q$ is the discharge in cubic meter per second $\left(\mathrm{m}^{3} \mathrm{~s}^{-1}\right)$, and $a$ and $b$ are location-dependent parameters. These parameters have been obtained with HEC-6 and depend on the local roughness and geometry. A quasi-2D approach is used to obtain the average number of flood days per year in the floodplains: the water levels in the main channel are extrapolated in the $y$-direction of the cross profiles, based on the river kilometer value $x$ for each cell $(x, y)$ in the floodplains. The critical discharge that causes inundation of the cell follows from the hydraulic parameters $(a, b)$ :

$Q_{c r i t}(x)=\left(\frac{z(x, y)}{a(x)}\right)^{\frac{1}{b(x)}}$,

where $z$ is the elevation of the cell $(x, y)$. For any location $(x, y)$ in the floodplains, the yearly average number of flood days $N_{f}$ is obtained by assuming a log-normal distribution for the daily average discharge and is given by:

$N_{f}(x, y)=\frac{365}{2}\left\{1-\operatorname{erf}\left[\frac{\ln \left(Q_{\text {crit }}(x)\right)-\mu(x)}{\sigma(x) \sqrt{2}}\right]\right\}$

where $\mu$ and $\sigma$ are the mean and standard deviation of the log-transformed daily average discharge. The probability distributions for the average daily discharge in the Elbe DSS are based on statistical analysis of discharges for the period 1964-1995 [29, 30]. The average number of flood days in the Middle Elbe region (Elbe km 214-274) is 32 days for the reference scenario, 31 days for the climate 
change scenario with a rainfall trend, 27 days for the scenario without a rainfall trend, and 25 days for the most probable scenario. This implies slightly drier conditions for the last two climate change scenarios.

\subsection{Statistical Model}

\subsubsection{Floodplain Vegetation}

The floodplain vegetation model forms the final component in the model chain and is based on an altered version [16] of the simple rule-based model MOVER2.2 (MOdel for VEgetation Response in Floodplains). This model was originally developed by the German Federal Institute of Hydrology to describe the expected dominant floodplain vegetation along the River Rhine. The output of MOVER 2.2 consists of 11 possible dominant vegetation types (Table 1) as a function of the distance to the main channel, the aggregated land class (cultivated land, grassland, or nature) and the number of flood days, which is the relevant parameter in view of the coupling to the rainfall-runoff and hydraulic models. The aggregated land classes are based on the 44 land-use types of the CORINE database [18]. The spatial distribution of the dominant vegetation types is calculated on the $100 \times 100 \mathrm{~m}$ grid of the digital elevation model [17]. In the rule table of the vegetation model, the number of flood days is accounted for in 10-day steps, but usually larger differences can result in a similar distribution pattern for the vegetation types.

\section{Model Coupling Method}

Consistency of the models is essential to ensure transparency of the DSS, enhance computational efficiency, and support the model selection process. Here, we define consistency as the condition that the output accuracy of

Table 1 The eleven possible vegetation types in the DSS version of MOVER2.2 [16]

\begin{tabular}{ll}
\hline Nr. & Dominant vegetation type \\
\hline 1 & Riverine pioneer habitats of floodplain lakes \\
2 & Elements of softwood floodplain forest \\
3 & Elements of hardwood floodplain forest \\
4 & Riverine Phalaris arundinacea reed \\
5 & Seasonally flooded riverine grassland \\
6 & Grassland of wet to moist sites \\
7 & Intensively used, species-poor, moist grassland \\
8 & Other riverine reeds \\
9 & Riverine herb fringes and herb meadows \\
10 & Dry and warm ruderal sites with dense vegetation \\
11 & Moist ruderal sites \\
\hline
\end{tabular}

the deterministic, rainfall-runoff model matches the required input accuracy for the statistical vegetation model. This accuracy cannot be determined by means of sensitivity and uncertainty analyses because the deterministic outcomes of the rainfall-runoff model are translated into statistical parameters before use in the vegetation model. This means that discharge time series of different accuracy can result in similar vegetation patterns if the mean and variance of the discharge time series remain the same, although too large deviations will lead to undesirable differences in the predicted pattern. To solve this problem, a number of artificial discharge time series are generated to reflect the hypothetical outcomes of the HBV calibrations of different quality levels. The quality of a rainfall-runoff model is usually expressed in terms of the Nash-Sutcliffe coefficient NS and the relative volume error RVE (see section 3.1.2). Both criteria measure the extent to which the model describes the data correctly. In this case, the NS value is chosen to assess the rainfall-runoff model accuracy, because it is a well-known criterion and it measures structural errors (as in RVE) as well as errors in the distribution of the discharge during the year.

To estimate the required accuracy of the HBV model prior to the calibration of the model, the hypothetical output $\left(Q_{g}\right)$ of HBV is generated from the observed discharge series $\left(Q_{\mathrm{o}}\right)$ and the statistical properties of the error time series $\left(Q_{\mathrm{o}}-Q_{\mathrm{m}}\right)$. This is done by adding an auto-correlated noise term $\varepsilon$ to the observed discharge $Q_{0}$ :

$Q_{\mathrm{g}}(t)=Q_{\mathrm{o}}(t)+\varepsilon(t)$,

where

$\varepsilon(t)=\delta(t) Q_{0}(t)+\alpha \varepsilon(t-1)$,

with $\delta(t)$ a time-varying scaling factor randomly drawn from a uniform distribution on the interval $[-\Delta,+\Delta]$ and $\alpha$ the auto-correlation coefficient of the error time series $\left(Q_{\mathrm{o}}-Q_{\mathrm{m}}\right)$. The error between the observed and generated discharge series (and thus the NS value) can be varied by adapting the parameter $\Delta$ in the range $[0,1]$. Using observed and modeled discharge values for the period 1979-1994, the autocorrelation coefficient $\alpha$ has been estimated for a time lag of 1 day for several locations along the Elbe river and was found to be 0.81 . This value corresponds well to the value of 0.82 found for the Meuse river [27]. The Meuse river is, like the Elbe river, a rain-fed river with a similar discharge pattern (e.g., maxima in the winter and minima in the summer). This results in similar differences between the observed and modeled discharge time series and thus in similar error time series.

To avoid confusion, it is necessary to distinguish between the required input accuracy $P_{1}$ of the vegetation model and the output accuracy $P_{2}$ of the rainfall-runoff model. The value of $P_{1}$ is expressed in terms of the minimal 
difference in the number of flood days that leads to a change in the vegetation type, and depends on the sensitivity of the vegetation model for changes in this input variable. Due to the rules underlying the model, MOVER2.2 does not respond to changes of 10 days or less in the number of flood days, which means that $P_{1}$ can be 10 days per year or more. The value of $P_{1}$ can be increased if a different, less sensitive vegetation model is used. The value of $P_{2}$ reflects the accuracy of a set of discharge years and is expressed in terms of the percentage of correct years. An artificially generated discharge year is considered to represent the data correctly if the difference between the observed and modeled number of flood days for that year does not exceed $P_{1}$. Equations 6 and 7 are used to generate auto-correlated discharge time series $\left(Q_{\mathrm{g}}\right)$ of different quality. The percentage of correctly predicted years $P_{2}$, which depends on the value of $P_{1}$, is stored for each time series. The appropriate NS value that corresponds to a particular combination of the values of $P_{1}$ and $P_{2}$ can then be obtained from the discharge time series that approaches the chosen value of $P_{2}$ best. The sensitivity of the NS values for simultaneous changes in the values of $P_{1}$ and $P_{2}$ was determined for the location at Wittenberg (Fig. 3) by means of example.

Figure 3 indicates that, for instance, a vegetation model requiring an accuracy of 20 days per year in the flood duration corresponds to an appropriate NS value of 0.85 for HBV based on $90 \%$ correctly predicted years. In principle, this value should be determined for each (sub)basin or river location for which observed discharge time series are available. Depending on the local hydraulic and geographical conditions, this may lead to different requirements for the calibration of the sub-basins.

\section{Results}

\subsection{Appropriate Coupling of Deterministic and Statistical Models}

Prior to application of the method, it is necessary to find the threshold NS value below which undesirable changes occur in the vegetation patterns, and to determine whether the resulting NS value is feasible. To answer the question whether the NS values fall within a feasible range, these were determined for the main gauge stations along the River Elbe (Table 2). The results of Table 2 are based on application of Eq. 5 to a $1-\mathrm{km}$-long section around each gauge station, using the spatial mean of the floodplain elevation. An exception is the location Barby. Here, the 1$\mathrm{km}$ section is taken downstream of the gauge station, because of the inflow of the River Saale tributary. The NS values in Table 2 are technically feasible if compared to the standards for well-performing rainfall-runoff models that are mentioned in the hydrological literature [33, 34]. It is found that well-calibrated rainfall-runoff models have NS values of 0.85 and higher. Values of 0.95 and higher are seldom reached, however. Ultimately, an increase of the noise in the time series will lead to changes in the statistical parameters in Eq. 5 and affect the vegetation patterns. To
Fig. 3 Sensitivity of the NS value at Wittenberg (Elbe $\mathrm{km}$ 214.1) for changes in the required input accuracy $P_{1}$ of the vegetation model and the percentage of correctly predicted years $P_{2}$ by the rainfall-runoff model

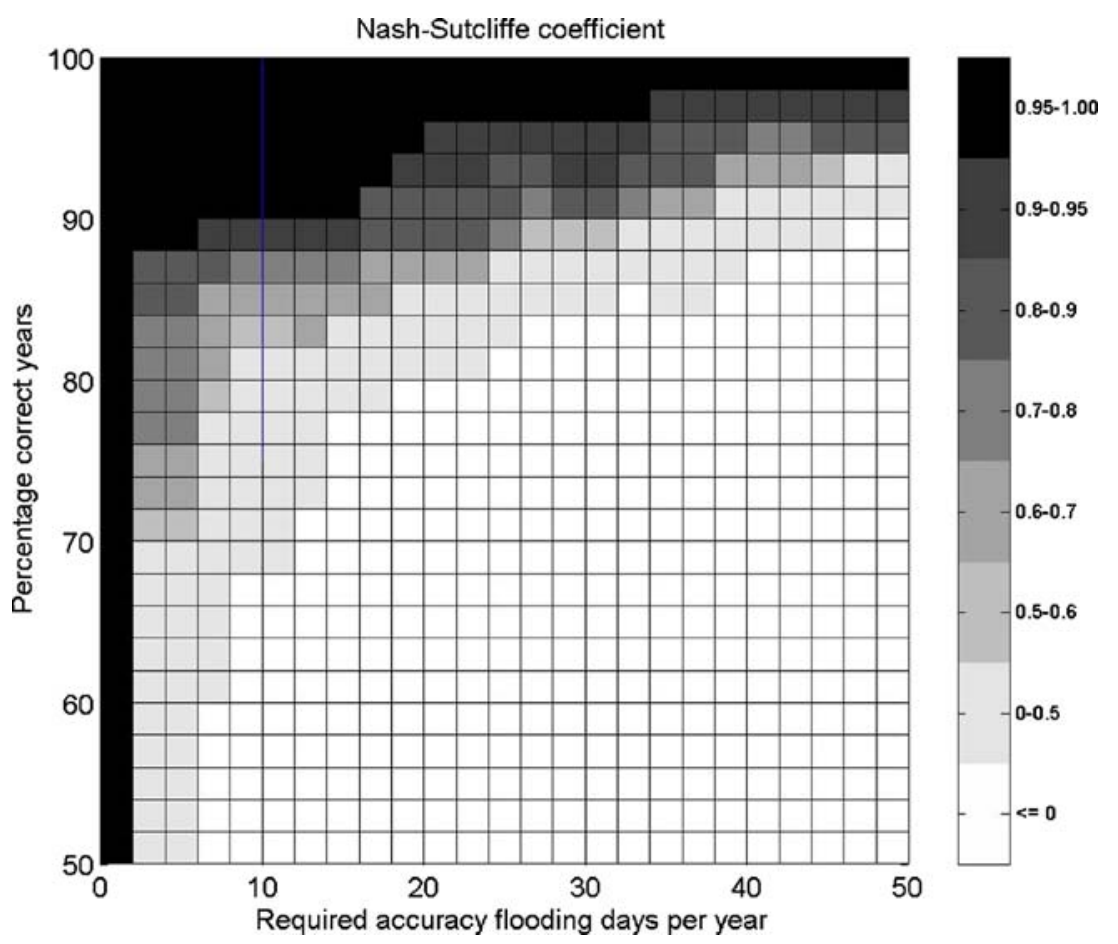


Table 2 Calibrated and appropriate NS values for HBV for the Elbe main gauge stations. The appropriate values are based on the required input accuracy of MOVER2.2 of ten flooddays per year and $P_{2}=90 \%$

\begin{tabular}{llll}
\hline Gauge station & $\begin{array}{l}\text { River stretch } \\
(\text { Elbe km) }\end{array}$ & $\begin{array}{l}\text { floodplain elevation } \\
(\mathrm{m}+\mathrm{NN})\end{array}$ & NS value \\
\hline Torgau & $154.6 \pm 0.5$ & $80.0 \pm 0.7$ & 0.91 \\
Wittenberg & $214.1 \pm 0.5$ & $67.0 \pm 0.6$ & 0.87 \\
Aken & $274.7 \pm 0.5$ & $55.0 \pm 0.4$ & 0.85 \\
Barby & $274.7-1.0$ & $50.7 \pm 0.5$ & 0.92 \\
Tangermünde & $388.2 \pm 0.5$ & $32.0 \pm 0.6$ & 0.93 \\
Wittenberge & $454.8 \pm 0.5$ & $20.5 \pm 0.3$ & 0.94 \\
\hline
\end{tabular}

find a threshold value for the NS coefficient discharge time series with decreasing NS value were generated by repeated application of Eqs. 6-7. Figure 4 shows the effect of increasing noise in the discharge time series on the vegetation pattern with the reference scenario between the towns of Wittenberg and Aken.

The results of Fig. 4 indicate that the noise corresponding to NS values of 0.8 and higher do not affect the vegetation patterns for the chosen river section significantly. The reason is that the difference in the average number of flood days is less than 10 days for most pixels. On the other hand, if the noise results in NS values of 0.6 and lower, this leads to clearly distinguish-
Fig. 4 Effect of noise in the reference time series on the vegetation pattern for the river section Wittenberg-Aken (Elbe $\mathrm{km}$ 214-274) with decreasing NS values in the range 1.0-0.5
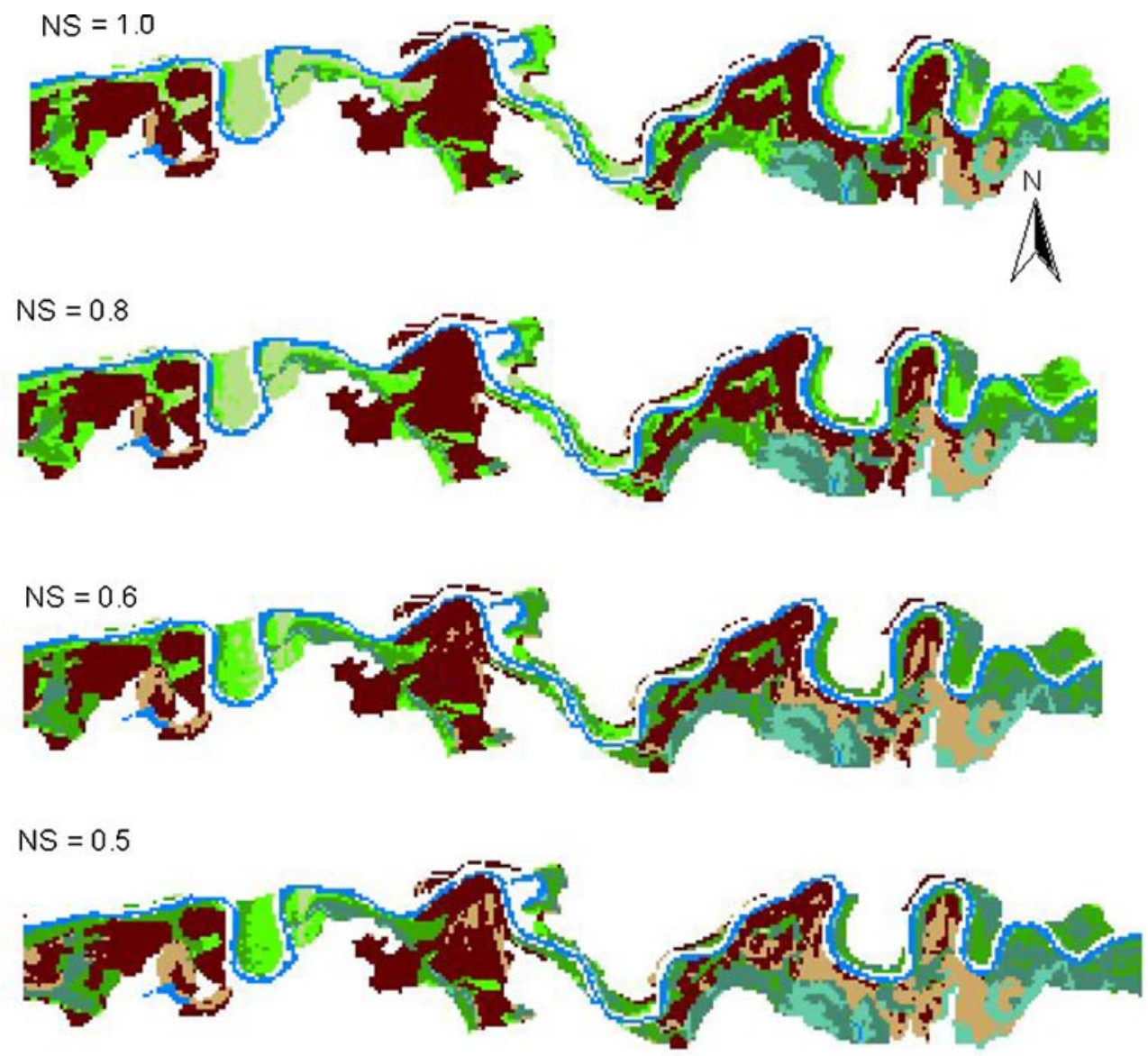

riverine pioneer habitats of floodplain lakes elements of softwood floodplain forest elements of hardwood floodplain forest riverine Phalaris Arundinacea reed seasonally flooded riverine grassland grassland of wet to moist sites intensively-used species poor , moist grassland other riverine reeds riverine herb fringes and herb meadows dry and warm ruderal sites with dense vegetation moist ruderal sites river no data or $<100 \mathrm{~m}$ from river 
able changes at several locations in the floodplains. The general conclusion is that, for the section WittenbergAken, a feasible NS value of 0.8 is appropriate. In comparison, the appropriate NS values shown in Table 2 are higher because the analysis pertains to small areas around the gauge stations, which are more sensitive to changes in the discharge statistics than the pattern for the section Wittenberg-Aken as a whole.

\subsection{Impact of Climate Change on the Floodplain Vegetation}

The application of the climate scenarios takes place as follows. By selecting the reference time series or one of the three climate scenarios, the user initiates a simulation run of HBV. In the Elbe DSS this results in a time series of the daily average discharge for the period 1979-1994 (reference scenario) or 2001-2015 (climate change) for each gauge station along the river. The mean and standard deviation of the log transformed discharge are obtained from the time series every $100 \mathrm{~m}$ along the main channel by means of linear interpolation. The average number of flood days in each cell is obtained by substitution of these two parameters in Eq. 5 for the corresponding river kilometer, and applied in the rule table of the MOVER 2.2 model [16], together with the distance to the main channel and the aggregated land use class, to obtain the dominant vegetation type. To examine the effect of climate change on the floodplain ecology along the river stretch Wittenberg (Elbe $\mathrm{km}$ 214.1)-Aken (Elbe km 274.4), a comparison was made between the predicted patterns of the dominant vegetation types for the reference time series and the three climate scenarios. A reasonable time span for the discharge statistics was obtained by selecting the discharge record for the five-year period 1979-1984 for the reference scenario, and for the period 2011-2015 for each of the other climate scenarios. For this time frame, the mean of
Fig. 5 Difference in the distribution of the dominant vegetation types between the reference case (a), and the climate scenarios with a rainfall trend (b), without a rainfall trend (c), and the most probable rainfall trend (d), for the river section Wittenberg-Aken (Elbe km 214-274) (a)

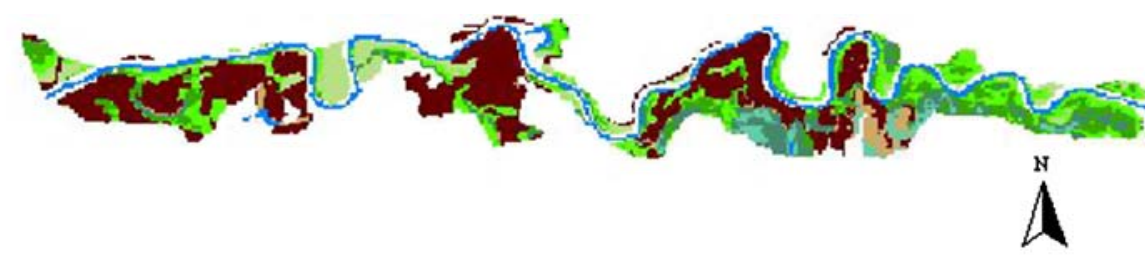

(b)

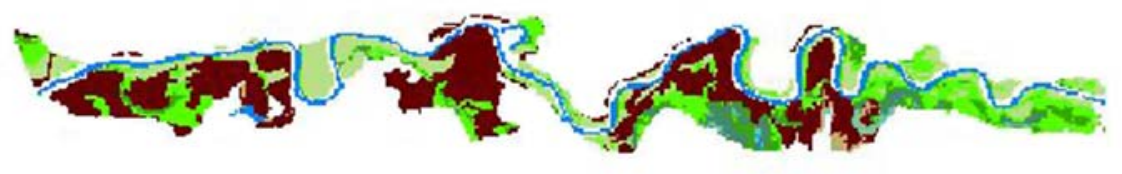

(c)

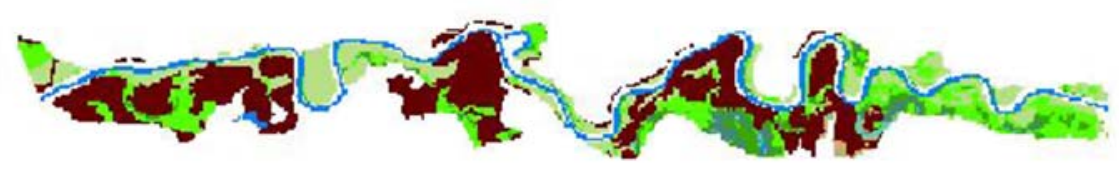

(d)

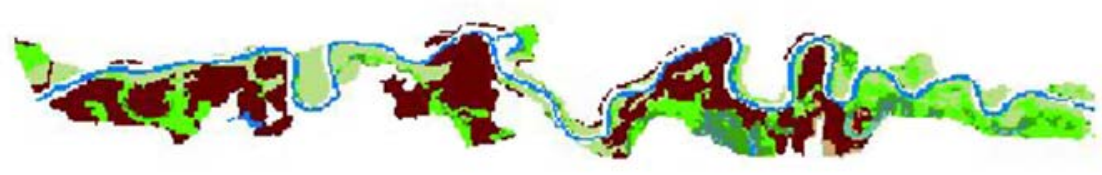

riverine pioneer habitats of floodplain lakes

elements of softwood floodplain forest

$0 \quad 24$ Kilometers elements of hardwood floodplain forest

riverine Phalaris Arundinacea reed

seasonally flooded riverine grassland

grassland of wet to moist sites

intensively-used species poor , moist grassland

other riverine reeds

riverine herb fringes and herb meadows

dry and warm ruderal sites with dense vegetation

moist ruderal sites

river

no data or $<100 \mathrm{~m}$ from river 
the discharge decreases for all three scenarios compared to the reference time series. Due to the definition of the trend classes the largest decrease occurs for the most probable rainfall trend scenario. Comparing the consequences for the vegetation patterns (Fig. 5) in the Wittenberg-Aken region little change is noticed with respect to the vegetation pattern for the reference case, although the percentage of different pixels is about $32 \%$ for the rainfall trend scenario and about $40 \%$ for the other two scenarios.

Nevertheless, some local differences can be noticed. In the east (Wittenberg area), the area of softwood declines for all three scenarios at the benefit of hardwood, which is more dominant under drier conditions according to the rule matrix of MOVER2.2 [16]. Furthermore, an increase of the area of grassland can be observed for several locations. In the west (Aken area), a section of softwood changes into hardwood as well. The local changes are less clear when one compares the spatial patterns as a whole, particularly at the scale of the complete river. Therefore, the differences between the scenarios along the complete modeled river stretch (Elbe km 135-502) have also been determined for each of the vegetation types separately (Fig. 6).

A clear change in the proportional distribution over the vegetation types can be observed for all three climate scenarios. The area occupied by pioneer habitats, reed, and seasonally flooded grassland declines for all scenarios, whereas the area of intensively used grassland shows a strong increase. The area occupied by the other vegetation types (soft- and hardwood, and grassland) show a small increase or decrease. Furthermore, the largest change occurs for the most probable rainfall scenario. Further analysis showed that the differences between the scenarios are sensitive to the selection of the time frames for which the discharge statistics are derived.

\section{Discussion}

The presence of different stakeholder interests and complex interaction of hydrological, hydraulic, socioeconomic and ecological processes call for integrated tools to support river managers. Decision-support systems, such as the recently completed prototype for the Elbe river, are useful platforms to integrate research models and data pertaining to different river processes and enable decision makers and stakeholders to examine and compare the effectiveness of different management strategies. Consistent coupling of models and data in a DSS ensures that obsolete costs and efforts spent on overly accurate models and data are avoided. Internal consistency of a DSS will not only help the developers collect models and data and facilitate the communication with the contributing scientists, but it will also
Fig. 6 Changes of the total area in square kilometers occupied by each vegetation type along the Elbe river ( $\mathrm{km} \mathrm{135-502)}$ under the three climate scenarios (rainfall trend, without rainfall trend, most probable) compared with the reference case

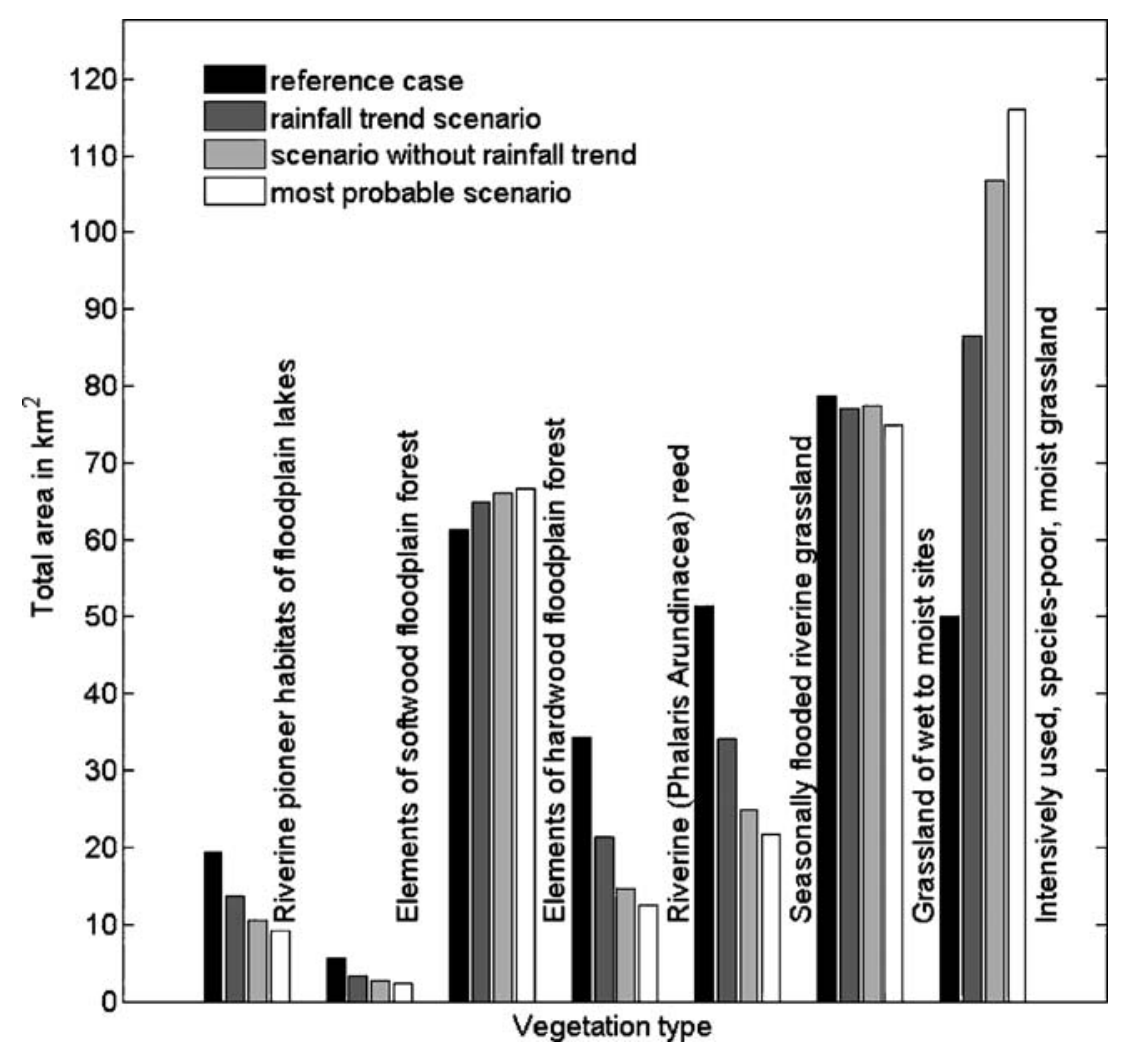


make the instrument more balanced and hence transparent for its users. Therefore, it is necessary to work with model quality standards during the design of a DSS. Moreover, such quality standards will be useful in the case of later changes to the design, for example, the integration of a rainfall-runoff model with models of different input sensitivity. The obvious approach to support the model selection process by means of sensitivity and uncertainty analyses fails when deterministic and statistical models are to be coupled because deterministic models of different quality can have identical statistical output. Here, this problem has been addressed by generating a large number of artificial discharge time series from the available observations and determining the Nash-Sutcliffe coefficient for each of them. Based on the sensitivity of the vegetation model to the number of flood days and a criterion for the acceptable percentage of years with an incorrect number of flood days, one can identify the most appropriate NS value. Depending on the purpose the method can be applied to specific locations (see Fig. 3 and Table 2), based on the required input accuracy of the last model in the model chain, or larger areas (see Fig. 4) by examining the effect of noise on the model outcomes. In both cases, the advantage is that an estimate of the appropriate NS value is obtained from easily generated artificial discharge time series without having to calibrate the rainfall-runoff model. This saves time and costs in the calibration process, and may also help identify which type of rainfall-runoff can be used in a DSS. An alternative way to determine the appropriate coupling between the deterministic and statistical model is to consider the signal-to-noise ratio of the model chain by comparing Figs. 4 and 5. The signal represented by the differences between the vegetation pattern for the reference scenario and those due to climate change (see Fig. 5) appear to be significant if compared to the noise represented by the differences between the vegetation patterns for NS values 0.8 and 1.0 (see Fig. 4). However, for NS values below 0.8 , the noise becomes significant compared to the signal and the accuracy of the hydrological model becomes too low. Although consistent DSS design pertains to other issues as well, the problem of coupling of deterministic and statistical models is often encountered and has not been solved so far. The artificially generated time series that represent the output of a deterministic model can both be applied to a river as a whole or at the level of subcatchments or locations of interest in this approach.

Acknowledgements This research has been funded by the German Ministry of Education and Science (BMBF) under project "Aufbau eines Pilot-DSS für die Elbe", project nr. FKZ 0339542A. The design of the Elbe DSS was coordinated by the German Federal Institute of Hydrology (Bundesanstalt für Gewässerkunde) at Koblenz.
Open Access This article is distributed under the terms of the Creative Commons Attribution Noncommercial License which permits any noncommercial use, distribution, and reproduction in any medium, provided the original author(s) and source are credited.

\section{References}

1. De Kok, J. L., \& Wind, H. G. (2003). Design and application of decision - support systems for integrated water management: lessons to be learnt. Physics and Chemistry of the Earth. Part B: Hydrology, Oceans and Atmosphere, 28, 571-578.

2. Berlekamp, J., Boer, S., Graf, N., Hahn, B., Holzhauer, H., Huang, Y., et al.(2005). Aufbau eines Pilot-Decision Support Systems (DSS) zum Flusseinzugsgebietsmanagement am Beispiel der Elbe-Abschlussbericht - Design of a pilot decision-support system for river-basin management with the Elbe river as example - Final report. Mitteilung Nr. 10, Projektgruppe ElbeÖkologie, Federal Institute of Hydrology, Koblenz (in German). http://elise.bafg.de/?3283.

3. Matthies, M., \& Berlekamp, J. (2006). System analysis for water quality management for the Elbe river basin. Environmental Modelling \& Software, 21(9), 1309-1318. doi:10.1016/ j.envsoft.2005.04.026.

4. Berlekamp, J., Lautenbach, S., Graf, N., Reimer, S., \& Matthies, M. (2007). Integration of MONERIS and GREAT-ER in the decision-support system for the German Elbe river basin. Environmental Modelling \& Software, 22(2), 239-247. doi:10.1016/j.envsoft.2005.07.021.

5. Rogers, P. (1978). On the choice of 'appropriate model' for water resources planning and management. Water Resources Research, 14, 1003-1010. doi:10.1029/WR014i006p01003.

6. Moussa, R., \& Bocquillon, C. (1996). Criteria for the choice of flood-routing methods in natural channels. Journal of Hydrology (Amsterdam), 186, 1-30. doi:10.1016/S0022-1694(96)03045-4.

7. Vreugdenhil, C. B. (2002). Accuracy and reliability of numerical river models. Journal of the American Water Resources Association, 38, 1083-1095. doi:10.1111/j.1752-1688.2002.tb05548.x.

8. Booij, M. J. (2003). Determination and integration of appropriate spatial scales for river basin modelling. Hydrological Processes, 17, 2581-2598. doi:10.1002/hyp.1268.

9. De Kok, J. L., \& Holzhauer, H. (2004). Pitfalls and challenges in the design and application of decision-support systems for integrated river-basin management. In J. Möltgen, \& P. Petry (Eds.), Interdisziplinäre Methoden des Flussgebietsmanagements - Interdisciplinary Methods of River-basin management, IFGI prints 21 (pp. 97-104). Münster, Germany: Institute for Geoinformatics, University of Münster.

10. Xu, Y. P., Booij, M. J., \& Mynett, A. E. (2007). An appropriateness framework for the Dutch Meuse decision support system. Environmental Modelling \& Software, 22, 1667-1678. doi:10.1016/j.envsoft.2007.01.002.

11. De Kort, I. A. T., \& Booij, M. J. (2007). Decision making under uncertainty in a decision support system for the Red River. Environmental Modelling \& Software, 22(2), 128-136. doi:10.1016/j.envsoft.2005.07.014.

12. Internationale Kommission zum Schutz der Elbe (IKSE) International Commission for the Protection of the Elbe River. (1995). http://www.ikse-mkol.org/.

13. UNESCO.(2006). http://www.biosphaerenreservatmittlereelbe.de

14. Bergström, S. (1995). The HBV model. In V. P. Singh (Ed.), Computer models of watershed hydrology. Water Resources Publications (pp. 443-476). Colorado: Highlands Ranch.

15. Otte-Witte, K., Adam, K., Meon, G., \& Rathke, K. (2002). Hydraulisch-morphologische Charakteristika entlang der Elbe 
(Hydraulic-morphological characteristics along the Elbe river. In F. Nestmann, \& B. Büchele (Eds.), Morphodynamik der Elbe, Endbericht des Verbundprojekts - Morphodynamics of the Elbe river - final project report (pp. 203-299). Karlsruhe: Institute of Water Resources Management, University of Karlsruhe (In German).

16. Fuchs, E., Giebel, H., Hettrich, A., Huesing, V., Rosenzweig, S., \& Theis, H.-J. (2002). Einsatz von ökologischen Modellen in der Wasser- und Schifffahrtsverwaltung, das integrierte Flussauenmodell INFORM - Employment of vegetation models for water and navigation management, the integrated floodplain model INFORM. Koblenz (in German): Mitteilung Nr. 25, Federal Institute of Hydrology (In German).

17. Bundesamt für Kartographie und Geodäsie (BKG) - Federal Agency for Cartography and Geodesy.(2003). Digitales Geländemodell 1:25.000 des Elbegebietes - Digital terrain model 1:25.000 of the Elbe river basin, on CD-ROM. - ATKIS* $D G M 25-D-V$, Bearbeitet durch Bundesanstalt für Gewässerkunde - modified by the Federal Institute of Hydrology, Frankfurt. http://www.bkg.bund.de.

18. European Environment Agency. CORINE Land cover database (n.d.). Retrieved 2002, from Website: http://dataservice.eea.eu.int/ dataservice/.

19. Jankiewicz, P., Kofalk, S., Spierling, C., \& Scholten, M. (2005). Digitale Erfassung von Informationen zur Höhe und Lage der Deichkronen an der Elbe und Aufbereitung für hydro-dynamische Modellierungen - Digitization of the status of the height and position of the dike crests along the Elbe river and preparation for hydrodynamic modelling. Mitteilung Nr. 9, Federal Institute of Hydrology, Koblenz (in German). http://elise.bafg.de/?1817.

20. Bundesministerium für Umwelt. Naturschutz und Reaktorsicherheit (BMU) - Federal Ministry for the Environment, Nature Conservation and Nuclear Safety, Hydrologischer Atlas von Deutschland - Hydrological Atlas of Germany, 2001. Berlin. http://had.bafg.de:8080/.

21. Blaney, H., \& Criddle, W. (1950). Determinating water requirements in irrigated areas from climatological and irrigation data. TP-96 p. 48. Washington: USDA.

22. Wendling, U., \& Müller, J. (1984). Entwicklung eines verfahrens zur abschätzung der verdunstung im winter (Development of a method to estimate the evapotranspiration in the winter). Zeitschrift für Meteorologie, 34(2), 82-85.

23. Gerstengarbe, F. W., \& Werner, P. C. (1997). A method to estimate the statistical confidence of cluster separation. Theoretical and Applied Climatology, 57, 103-110. doi:10.1007/ BF00867981.
24. Werner, P. C., \& Gerstengarbe, F. W. (1997). Proposal for the development of climate scenarios. Climate Research, 8(3), 171182. doi:10.3354/cr008171.

25. Roeckner, E., Arpe, K., Bengtsson, L., Christoph, M., Claussen, M., Dümenil, L., et al. (1996). The atmospheric general circulation model ECHAM-4: Model description and simulation of present-day climate, Report vol. 218. Hamburg: Max Planck Institute for Meteorology.

26. International Panel for Climate Change (IPCC) (2001). Climate Change 2000, Summary for policy makers. Cambridge, UK: Cambridge University Press.

27. Booij, M. J. (2005). Impact of climate change on river flooding assessed with different spatial model resolutions. Journal of Hydrology (Amsterdam), 303, 176-198. doi:10.1016/j.jhydrol. 2004.07.013

28. Krysanova, V., Bronstert, A., \& Wohlfeil, D.-I. (1999). Modelling river discharge for large drainage basins: from lumped to distributed approach. Hydrological Sciences Journal, 44, 313-331.

29. Helms, M., Büchele, B., Merkel, U., \& Ihringer, J. (2002a). Statistical analysis of the flood situation and assessment of the impact of diking measures along the Elbe (Labe) river. Journal of Hydrology (Amsterdam), 267, 94-114. doi:10.1016/S0022-1694(02)00143-9.

30. Helms, M., Ihringer, J., \& Nestmann, F. (2002b). Analyse und simulation des abflussprozesses der Elbe - Analysis and simulation of the flow process of the Elbe river. In F. Nestmann, \& B. Büchele (Eds.), Morphodynamik der Elbe, Endbericht des Verbundprojekts -Morphodynamics of the Elbe river - final project report (pp. 91-202). Karlsruhe: Institute of Water Resources Management, University of Karlsruhe (In German).

31. Nash, J. E., \& Sutcliffe, J. V. (1970). River flow forecasting through conceptual models. Part I. A discussion of principles. Journal of Hydrology (Amsterdam), 10, 282-290. doi:10.1016/ 0022-1694(70)90255-6.

32. Hydrologic Engineering Center (HEC). US Army Corps of Engineers (1992). Guidelines for the Calibration and Application of Computer Program HEC-6, Training Document No. 13, Davis, CA. http://www.hec.usace.army.mil/.

33. Seibert, J., Uhlenbrook, S., Leibundgut, C., \& Halidin, S. (2000). Multiscale calibration and validation of a conceptual rainfall-runoff model. Physics and Chemistry of the Earth part B, 25, 59-64.

34. Middelkoop, H., Daamen, K., Gellens, D., Grabs, W., Kwadijk, J. C. J., Lang, H., et al. (2001). Impact of climate change on hydrological regimes and water resources management in the Rhine basin. Climatic Change, 49, 105-128. doi:10.1023/ A:1010784727448. 